\title{
Katyonik Asfalt Emülsiyon Stabilizasyonlu Zeminin Esnek Üstyapı Tabaka Kalınlığına Etkisi
}

\author{
Mustafa ÇALIŞICI ${ }^{* 1}$, Ertan KOÇ², Ömer Faruk CANSIZ ${ }^{1}$ \\ ${ }^{1}$ İskenderun Teknik Üniversitesi, Mühendislik ve Doğa Bilimleri Fakültesi, İnşaat Mühendisliği \\ Bölümü, İskenderun, Hatay \\ ${ }^{2}$ Devlet Hava Meydanları Işsletmesi, İnşaat ve Emlak Dairesi Başkanlı̆̆ , Ankara
}

Geliş tarihi: 06.02.2017 Kabul tarihi: 31.05.2017

\section{$\ddot{\mathbf{O} z}$}

Yük ve yolcu taşımacıllğının büyük oranda karayoluyla yapıldığı ülkemizde gelişen otomotiv sektörünün de etkisiyle daha yüksek yük kapasiteli kamyonların yollarda olması daha dayanıklı yolların imalatı ihtiyacını doğurmaktadır. Zemin taşıma gücünün artması esnek kaplamalarda maliyeti en yüksek kısım olan üst yapının daha dayanıklı ve daha az maliyetli olmasına sebep olacaktır. Bu çalışmada iki farklı zeminde yapılan C60B2 katyonik asfalt emülsiyonu ile stabilizasyonun zeminlerin Kaliforniya Taşıma Gücü (CBR) değerlerine etkileri incelenmiştir. CBR'da meydana gelen değişimin esnek üstyapı tabaka kalınlıklarına olan etkileri ise AASHTO 93 yöntemiyle tasarlanan üstyapı hesabıyla ortaya konmuştur. Sonuçta C60B2 ile stabilize edilmiş zeminlerde CBR artışılla üstyapı tabakalarının kalınlığının belirgin ölçüde azaldığı ya da esnek üstyapının taşıma kabiliyetinin arttığı görülmüştür.

Anahtar Kelimeler: C60B2, Stabilizasyon, Esnek üstyap1, AASHTO 93

\section{The Effect of Cationic Bitumen Emulsion Stabilized Subgrade on Tickness of Layers of the Flexible Pavement}

\begin{abstract}
In our country in which cargo and passenger transportation are mainly done on land routes, having more frequent higher load capacity trucks because of the improving automobile industry, necessitates more durable road constructions. The increase of the bearing capacity of soil enable cheaper and more durable superstructure, which is the most expensive part of flexible pavements. In this study, the effects on CBR value of two different soils which are stabilized with C60B2 cationic asphalt emulsion are investigated. Changing CBR values' effects on the thickness of flexible superstructure layers are revealed by the superstructure calculation which is designed by the AASHTO 93 method. Finally, it has been observed that on soils which are stabilized with C6B02, increase of CBR significantly decreases superstructure's layer thicknesses and improves flexible superstructure's bearing ratio.
\end{abstract}

Keywords: C60B2, Stabilisation, Flexible pavement, AASHTO 93

*Sorumlu yazar (Corresponding author): Mustafa ÇALIŞICI, mustafa.calisici@iste.edu.tr 


\section{GíRIŞ̧}

Teknolojik, sosyo-ekonomik ve sosyo-kültürel açıdan sürekli gelişen ülkemizde bunlara paralel olarak ulaşım sektörü de büyük gelişme içerisindedir. Ulaşım sektörünün büyümesiyle yeni ulaştırma yollarına ihtiyaç duyulmakta olup devletimiz Kamu-Özel iş birliğiyle bu ihtiyaca cevap vermeye çalışmaktadır. Tasarlanması ve yapılması yoğun çabalar gerektiren ulaştırma yolları aynı zamanda devlete büyük finansal yükler de getirmektedir.

$\mathrm{Bu}$ çalışmada esnek kaplama özelliği taşıyan ulaştırma yollarının (karayolu, pist vs.) zemininin C60B2 katyonik bitümlü emülsiyonuyla stabilize edilmesi sonucu yeni tabaka kalınlıklarının belirlenerek bu stabilizasyonun esnek üstyap1 üzerine etkileri incelenmiştir.

Yapılarda olduğu gibi yol kaplamalarında da zemin stabilitesi ve/veya dolguda kullanilan zeminin özellikleri üstyapıyı önemli ölçüde etkiler. Zira zeminler kaplamaların temeli olduğundan dolayı kaplamanın ve trafik yüklerinin yarattığ gerilmelere emniyetle karşı koyabilmelidir. Çevre ve iklim koşullarından ötürü zemin özelliklerindeki değişikliklerin zemin taşıma gücünde azalmalara veya ilave gerilmelere neden olmayacak seviyede kalması gerekmektedir.

Yol kaplamalarının performansı, ömrü, bakım masrafları, vb. nitelikler kaplamanın tasarımı, kullanılan malzemeler, yapım tekniği gibi hususlara bağlı olduğu kadar, zeminin stabilitesiyle de doğrudan ilgilidir. İnşa edilen yol kaplamaları için uygun olmayan zeminler sslah edilerek yeterince stabil bir hale dönüştürülmelidir. Zeminlerin 1slahı zemin cinslerine göre birçok farklı yöntemle yapılabilmektedir. Katkı maddeleri katılarak zemin stabilizasyonunun sağlanması da bu yöntemlerden bir tanesidir. Zeminin bir takım olumsuz özelliklerinin uygun bir stabilizasyon tekniği ile iyileştirilmesi mümkündür. Çimento, kireç, uçucu kül, bitüm vs. gibi katkı maddeleri zemin stabilizasyonunu sağlamada en çok tercih edilen stabilizasyon yöntemleridir.
Ülkemizde mevcut karayolu üstyapılarının neredeyse tamamı esnek üstyapı olup bunun büyük kısmı sathi kaplamadır. Gerek bitümlü sıcak karışım kaplama (BSK), gerekse sathi kaplama olsun esnek üstyapılarda zemin belirli bir taşıma gücüne sahip olmalıdır, aksi durumda trafik etkilerini daha geniş alanlara yaymak için daha kalın tabakalara ihtiyaç duyulacaktır. Tabakaların kalınlaşması ise doğrudan maliyeti ve inşaat süresini arttırabilecek etkilere sahiptir.

Bitüm, asfalt gibi petrolden elde edilen maddeler siyah, yapışkan ve sıcakken sıvı olan ürünlerdir. $\mathrm{Bu}$ maddeler genel olarak taneler arasında bağlayıcılık etkileri ile geçirimsizlik sağladıkları gibi zemini sudan da koruyabildiklerinden dolayı değişik çevre şartlarında zemin dayanımını arttırmak amaciyla zemin stabilizasyonlarında kullanabilmektedirler [1].

Üst yapı dizaynı ampirik ve mekanistik-ampirik olmak üzere iki şekilde yapılabilmektedir. Ampirik bir yöntem olan AASHTO 93 tasarım yöntemi genel olarak zemin taşıma gücünü ve trafik değerini esas almaktadır [2].

\section{2. ÖNCEKİ ÇALIŞMALAR}

Literatürde farklı zemin türleri için farklı malzemelerle yapılan iyileştirmelerin zemin taşıma gücüne (CBR) veya üstyapıya olan etkileri ile ilgili birçok çalışma bulunmaktadır [2-5].

Kök ve arkadaşları [2] tarafından çimento stabilizasyonu ile taşıma gücü artırılan zeminler üzerine inşa edilecek esnek üstyapıların maliyeti ile stabilizasyon maliyeti arasındaki ilişki araştırılmıştır. Sonuçta artan CBR değerlerine karşılık ele alınan düşük, orta ve yüksek trafik değerleri için üstyapı maliyetinin \%15 CBR değerine kadar hızlı, daha sonra ise yavaş bir şekilde azaldığını, stabilizasyon maliyetinin ise CBR miktarındaki artış ile sürekli arttığını tespit etmişlerdir. 
Kolias ve arkadaşları [3] ince gradasyonlu killi zeminlerde (CL-CH) yüksek kalsiyum içerikli uçucu kül ve çimento ile stabilizasyonun etkinliğini incelemişlerdir. Değişik oranlardaki uçucu kül ve çimento karışımlı numunelerin elastisite modüllerini, 90 günlük basınç dayanımlarını ve CBR değerlerini tespit etmişlerdir. Uçucu kül ve çimento ile iyileştirilmiş killi zemin üzerindeki esnek üstyapının analizini yaparak geleneksel üstyapılar ile karşılaştırmış ve stabilizasyonun teknik faydalarını açıkça ortaya koymuşlardır.

Şenol ve arkadaşları [4] farklı tesislerden elde ettikleri yüksek oranda $\mathrm{CaO}$ ve karbon içeren uçucu küllerin yumuşak zeminlerin stabilizasyonundaki etkilerini incelemiş, kül içeriğinin artması ile zemin cinslerine göre CBR değerinin ve basınç mukavemetinin belirgin oranlarda arttığını, en fazla artışın uçucu kül içerikli CL sınıfındaki zeminlerde olduğunu saptamışlardır.

Eren ve Filiz [5] yaptıkları çalışmada değişik oranlarda çimento ve kireç katkılı zeminin CBR değerlerini incelemişlerdir. Kireç oranının belirli bir değere kadar CBR değerini arttırabildiğinin belirlendiği çalışmada aynı zamanda kireç katkılı zeminin şişmeye karşı da daha dirençli olduğunu tespit etmişlerdir.

\section{MATERYAL VE METOT}

Kullanılacak asfaltın uygulama sıcaklığı, bitümlü malzemelerin cinslerine göre değişmektedir. C60B2 asfalt emülsiyonu için uygun sicaklık $50-85^{\circ} \mathrm{C}$ olarak belirlenmiştir [6]. Zemin-Asfalt emülsiyonu stabilizasyonu sicak havalarda yapılmalıdır. $10^{\circ} \mathrm{C}$ 'den daha düşük hava sicaklıklarında likit asfaltlarla zemin stabilizasyonu yapılmamalıdır [7]. İnşaat sırasında zeminin rutubeti optimum su muhtevasindan daha az olmalıdır. Asfalt, zeminle bu su muhtevasında karıștırılmalı ve sıkıștırılmadan önce karışımın sertleşmesini sağlamak için havalandırılarak içindeki uçucu maddenin çıkmasına müsaade edilmelidir [8].
Bu çalışmada zemin, asfalt emülsiyonu ve stabilize edilen numunelerle ilgili tüm deneyler Ulaştırma, Denizcilik ve Haberleşme Bakanlığı, Altyapı Yatırımları Genel Müdürlüğü, Araştırma Dairesi Başkanlığı bünyesinde bulunan asfalt ve zemin laboratuvarlarında yapılmıştır.

\subsection{Zemin Numuneleri}

Stabilizasyonda iki tip zemin kullanılmıştır. Bunlardan A tipi zeminde ince malzeme oranı daha fazla iken B tipi zeminde ise kaba agrega oranı yüksektir. Zemin numuneleri Karayolları ve AASHTO şartname limitlerini sağlayacak şekilde hazırlanmıştır. Çizelge 1 ve Çizelge 2'de kullanılan zemin numunelerinin etüv öncesi ve sonrası gradasyonu ve şartname limitleri verilmiştir.

Çizelge 1. Etüv öncesi numune gradasyonu

\begin{tabular}{|c|c|c|c|}
\hline Elek No & $\begin{array}{c}\text { Şartname } \\
\text { Limitleri } \\
\% \text { Geçen }\end{array}$ & $\begin{array}{c}\text { A Tipi } \\
\text { Zemin } \\
\% \text { Geçen }\end{array}$ & $\begin{array}{c}\text { B Tipi } \\
\text { Zemin } \\
\% \text { Geçen }\end{array}$ \\
\hline 4 & $50-100$ & 85.00 & 75.00 \\
\hline 40 & $35-100$ & 55.00 & 45.00 \\
\hline 200 & $10-50$ & 20 & 20 \\
\hline
\end{tabular}

Çizelge 2. Etüv sonrası numune gradasyonu

\begin{tabular}{|c|c|c|c|}
\hline Elek No & $\begin{array}{c}\text { Şartname } \\
\text { Limitleri } \\
\% \text { Geçen }\end{array}$ & $\begin{array}{c}\text { A Tipi } \\
\text { Zemin } \\
\% \text { Geçen }\end{array}$ & $\begin{array}{c}\text { B Tipi } \\
\text { Zemin } \\
\% \text { Geçen }\end{array}$ \\
\hline 4 & $50-100$ & 89.50 & 78.50 \\
\hline 40 & $35-100$ & 56.90 & 51.50 \\
\hline 200 & $10-50$ & 21.50 & 22.50 \\
\hline
\end{tabular}

Zeminler üzerinde Modifiye Proctor Deneyleri yapılmış olup maksimum kuru birim hacim ağırlığ ve optimum su muhtevası değerleri bulunarak Şekil 1 ve Şekil 2'de gösterilmiştir. 


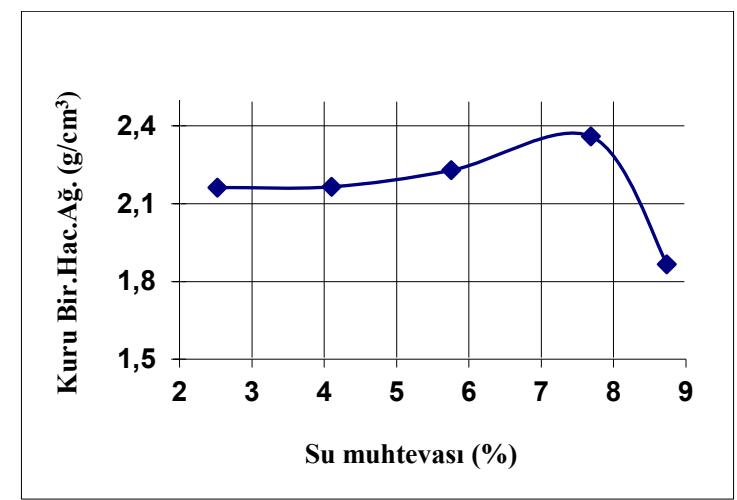

Şekil 1. A tipi zemin için zeminin kuru birim hacim ağırlık-su muhtevası ilişkisi

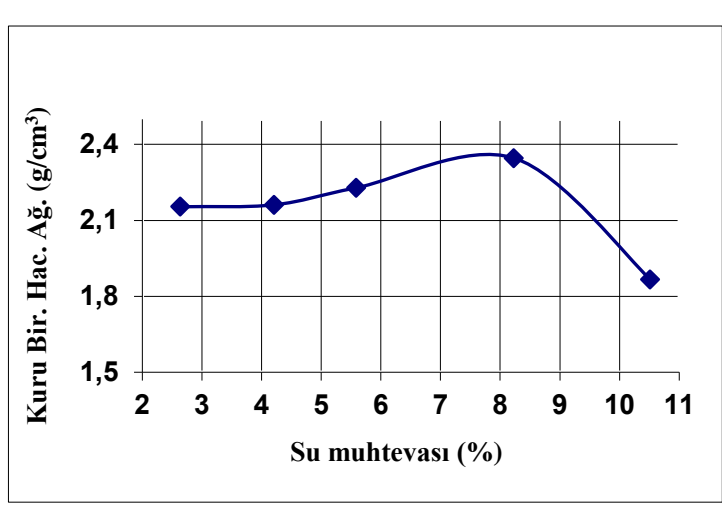

Şekil 2. B tipi zemin için zeminin kuru birim hacim ağırlık-su muhtevası ilişkisi

\subsection{Katyonik Asfalt Emülsiyonu (C60B2)}

Zemin stabilizasyonunda kullanılan C60B2 emülsiyonu önceki şartname de CRS-1 katyonik asfalt emülsiyonu olarak da bilinen çabuk kesilen bir tür bitüm emülsiyonudur [9]. Şartnamede C60B2 asfalt emülsiyonunun viskozite değerinin 40-100 sn. arasında olması gerektiği belirtilmiştir [10]. Laboratuvarda yapılan Saybolt viskozite deneyi sonucunda ise bu değer 46 sn olarak bulunmuştur. Aynı zamanda kullanılan C60B2 asfalt emülsiyonunun özgül ağırlığı piknometre deneyi ile $1,0125 \mathrm{gr} / \mathrm{cm}^{3}$ olarak bulunmuştur.

\subsection{Marshall Stabilite Testi}

$\mathrm{Bu}$ çalışmada $\mathrm{A}$ ve $\mathrm{B}$ tipi zeminlerde ağırlıkça $\%$ 1-2-3-4-5 oranlarında asfalt emülsiyon katkı1ı (stabilize edilmiş) numuneler Marshall Stabilite testine tabi tutulmuştur. Her bir yüzde değeri için deneye tabi tutulan Marshall numunelerinin ortalaması alınarak test sonuçları belirlenmiştir. Test sonuçlarına göre elde edilen maksimum stabilite değerini sağlayan optimum asfalt miktarları yüzdece belirlenmiştir.

Numuneler optimum su muhtevasının biraz altında su $(50 \mathrm{ml})$ ve $\%$ 1-2-3-4-5 oranlarında asfalt emülsiyonu ile karıştırılarak dakikada 90 devir yapan bir mikserde 1 dakika boyunca karıştırılmış ve $100 \mathrm{~mm}$ çapında $75 \mathrm{~mm}$ derinliğindeki kalıplara yerleştirilmiştir. $4,5 \mathrm{~kg}$ ağırlığında tokmağın $45 \mathrm{~cm}$ yükseklikten numunelerin her iki yüzüne 75 'er defa düşürülerek sıkıştırılması sağlanmıştır. Sonuçta elde edilen numuneler Marshall Stabilite testine tabi tutulmuş ve sonuçlar Şekil 3'de gösterilmiş̧ir.

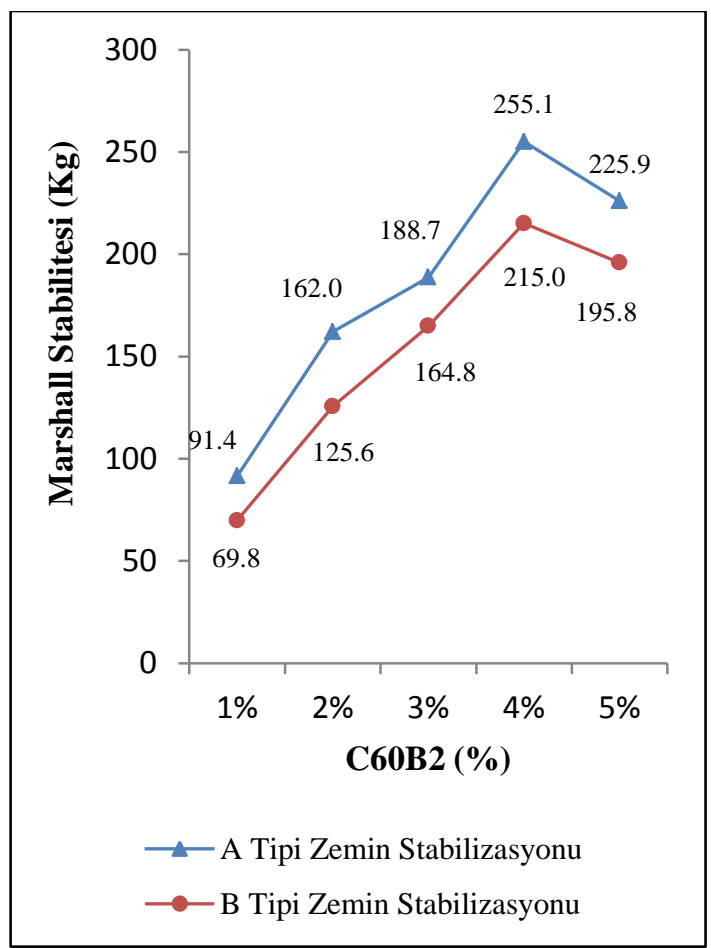

Şekil 3. Marshall Stabilitesi test sonuçları

Şekil 3'den görüldüğü gibi her iki zemin numunesi için de optimum asfalt oranı $\% 4$ olarak elde edilmiştir. 


\subsection{Kaliforniya Taşıma Oranı Testi (CBR)}

Optimum asfalt emülsiyonu oranları ile karıştırılarak nemli bir ortamda 7 gün kür edilen stabilize edilmiş A ve B tipi numuneler kesit tasarımlarında önemli bir kriter olan CBR (Kaliforniya Taşıma Oranı) deneyine tabi tutulmuştur. Her iki tip zemin stabilizasyonunda da optimum emülsiyon oranı olan $\% 4$ asfalt emülsiyonu ile stabilize edilmiş numunelerde 2,5 ve $5 \mathrm{~mm}$ penetrasyon değerini sağlayan yük değerlerinin, \%100 CBR değerine karşılık gelen standart yüklere oranından elde edilen en büyük değer, zeminin CBR değeri olarak alınmıştır [11]. Stabilize edilmemiş zemin numunelerinin de CBR değerleri hesaplanarak 2 adet $\mathrm{CBR}$ değeri daha elde edilmiş ve tasarım kriteri olarak dizaynda kullanılmıştır.

Deney yapılırken 45 kg'lık yük, dakikada 1,2 mm hızla numuneye uygulanmış olup ölçülen değerler Şekil 4'de gösterilmiştir.

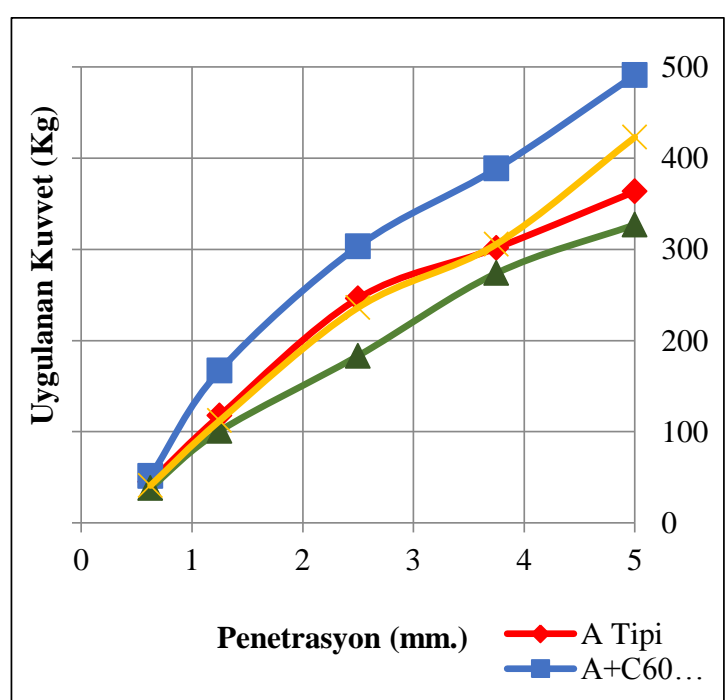

Şekil 4. Kuvvet-penetrasyon grafiği

Şekil 4'de görüldüğü gibi Marshall stabilite testinde daha yüksek mukavemet değerini veren A tipi stabilize edilmiş zeminin CBR değerleri beklenildiği gibi $\mathrm{B}$ tipine göre daha yüksek çıkmıştır. Şekil 4'den elde edilen kuvvetpenetrasyon değerlerine göre hesaplanan CBR değerleri ise Çizelge 3'de görülmektedir.
Çizelge 3. Stabilizeli ve stabilizesiz A ve B tipi zeminlerin CBR değerleri

\begin{tabular}{|c|c|c|}
\hline Zemin Türü & $\begin{array}{c}\text { Penetrasyon } \\
(\mathrm{mm})\end{array}$ & CBR $(\%)$ \\
\hline A Tipi & 2,50 & 18,09 \\
\hline A Tipi+C60B2 & 5,00 & 24,05 \\
\hline B Tipi & 5,00 & 16,02 \\
\hline B Tipi+C60B2 & 5,00 & 20,72 \\
\hline
\end{tabular}

Çizelge 3'de görüldüğü gibi stabilizasyonu yapılmamış A tipi zeminde CBR değeri 18,09 iken, \% 4 C60B2 ile stabilize edilmiş numunenin CBR değeri 24,05 olarak elde edilmiştir. Bu sonuca göre C60B2 ile stabilizasyon A tipi zemin için zemin taşıma gücünde yaklaşık \%33'lük bir artış sağlamıştır. Yine Çizelge 3'e dikkat edilirse daha zayıf olan B tipi zeminin stabilizasyon yapılmadan önceki CBR değeri 16,02 iken \%4 C60B2 ile stabilizasyonu sonrası numunenin CBR değeri 20,72 olarak elde edilmiştir. Bu sonuca göre C60B2 ile stabilizasyon B tipi zemin için zemin taşıma gücünde yaklaşık \%30'lük bir artış sağlamıştır.

Zayıf zeminlerde stabilizasyon daha fazla önem arz ettiğinden dolayı bu aşamadan sonra üstyap1 dizayn hesabında taşıma gücü daha düşük olan B tipi zeminler dikkate alınacaktır.

\subsection{C60B2 Stabilizasyonunun Esnek Üstyapı Tabaka Kalınlığına Etkisi}

Bu çalışmada esnek üstyapı dizaynında ülkemizde de halihazırda kullanılmakta olan AASHTO 93 tasarım yöntemi kullanılmıştır. $\mathrm{Bu}$ yöntemde tasarım temel olarak zemin taşıma gücü, trafik yükü ve çevre etkilerini dikkate alarak yapılmaktadır. AASHTO 93 metodunda zemin taşıma gücü olarak kullanılan $\mathrm{M}_{\mathrm{R}}$ değeri, CBR yardımıyla ampirik bir formül olan Eşitlik 1'deki bağıntı ile hesaplanabilmektedir [12].

$M_{R}=1500 \times C B R$

Sonuçta C60B2 asfalt emülsiyonunun zeminde meydana getirdiği iyileşmenin esnek üstyapıya 
etkilerini ortaya koymak için stabilizasyonlu ve stabilizasyonsuz zemin için tasarımlar mevcut bir yol ağındaki veriler dikkate alınarak yapılmıştır. Tasarım kriterleri olarak, Iğdır-Ağrı arasına yapılması planlanan 2 şeritli 2 yönlü bölünmüş toplam 4 şeritli yol, kaplama genişliği $13 \mathrm{~m}$, taban genişliği $20 \mathrm{~m}$, zemin - C60B2 asfalt emülsiyon stabilizasyonu $10 \mathrm{~cm}$ kalınlığında kabul edilmiştir. Ayrıca yolun Servis yeteneği $(\mathrm{Pt})=2,6$ ve Bölge faktörü $\mathrm{R}=1,0$ olarak alınmıştır. Iğdır-Ağrı arası trafik akış dağılım verileri 2015 karayolları istatistiklerinden elde edilmiş ve Çizelge 4'de sunulmuştur [13].

Çizelge 4. Iğdır-Ağrı arası karayolu 2015 yılına ait yıllık ortalama günlük trafik verileri

\begin{tabular}{|c|c|c|}
\hline Araç türü & YOGT & Y1llık artıs miktarı (\%) \\
\hline Kamyon & 667 & \multirow{2}{*}{3} \\
\hline Treyler & 240 & \\
\hline Otobüs & 53 & \multirow{2}{*}{5} \\
\hline Otomobil & 3500 & \\
\hline
\end{tabular}

Stabilizasyonlu ve stabilizasyonsuz zeminler için ayrı ayrı esnek üstyapı dizayn hesabı AASHTO 93 yöntemiyle yapılmış, hesap sonucu tabaka kalınlıkları Çizelge 5 ve Çizelge 6'daki gibi bulunmuştur.

Çizelge 5. Iğdır-Ağrı arası karayolunda hesaplanan stabilizasyon öncesi zemin için üstyapı kalınlıkları (üstyapı kesiti) $(\mathrm{CBR}=\% 16)$

\begin{tabular}{|c|c|c|}
\hline $5 \mathrm{~cm}$ & Aşınma Tabakas 1 & \multirow{3}{*}{$38 \mathrm{~cm}$} \\
\hline $8 \mathrm{~cm}$ & Binder Tabakas1 & \\
\hline $25 \mathrm{~cm}$ & Zemin (CBR \%16) & \\
\hline & Plent-mix Temel & \\
\hline
\end{tabular}

Çizelge 6. Iğdır-Ağrı arası karayolunda hesaplanan stabilizasyon sonrası zemin için üstyapı kalınlıkları (üstyapı kesiti) $(\mathrm{CBR}=\% 20)$

\begin{tabular}{|c|c|c|}
\hline $5 \mathrm{~cm}$ & Aşınma Tabakası & \multirow{3}{*}{$33 \mathrm{~cm}$} \\
\hline $8 \mathrm{~cm}$ & Binder Tabakası & \\
\hline $20 \mathrm{~cm}$ & Plent-mix Temel & \\
\hline \multirow[t]{2}{*}{$10 \mathrm{~cm}$} & $\begin{array}{c}\text { Zemin+\% } 4 \text { C60B2 } \\
(\text { CBR \%20) }\end{array}$ & \\
\hline & Zemin (CBR \%16) & \\
\hline
\end{tabular}

Çizelge 5 ve Çizelge 6 karşılaştırıldığında stabilizasyon sonrası \%33 yükselen zemin CBR değeri toplamda $38 \mathrm{~cm}$ olan kaplama kalınlığını 33 cm'ye düşürmüştür. Zeminin stabilizasyonu sonrası artan taşıma gücü ile temel tabakasındaki azalma zaten beklenen bir sonuçtur. Plent-mix temel olarak tasarlanmış temelin tabaka kalınlığının yaklaşık \%20 oranında azalmış olduğu hesaplanabilir.

Sonuçların daha belirgin görülebilmesi için trafik yüklerinin yaklaşık 4,5 kat daha fazla olduğu Hatay - Kahramanmaraş şehirleri arasındaki trafik değerleri dikkate alınarak aynı hesap yapıldığında ise Çizelge 7 ve Çizelge 8'de verilen üstyapı en kesit kalınlıkları hesaplanmıştır.

Çizelge 7. Hatay-Kahramanmaraş aras1 karayolunda hesaplanan stabilizasyon öncesi zemin için üstyapı kalınlıkları (üstyapı kesiti) $(\mathrm{CBR}=\% 16)$

\begin{tabular}{|c|c|c|}
\hline $5 \mathrm{~cm}$ & Aşınma Tabakası & \multirow{2}{*}{$65 \mathrm{~cm}$} \\
\hline $8 \mathrm{~cm}$ & Binder Tabakası & \multirow{2}{*}{$65 \mathrm{~cm}$} \\
\hline & Plent-mix Temel & \\
\hline & Zemin (CBR \% 16) & \\
\hline
\end{tabular}

Çizelge 8. Hatay-Kahramanmaraş aras1 karayolunda hesaplanan stabilizasyon sonrası zemin için üstyapı kalınlıkları (üstyap1 kesiti) $(\mathrm{CBR}=\% 20)$

\begin{tabular}{|c|c|c|}
\hline $5 \mathrm{~cm}$ & Aşınma Tabakas1 & \multirow{2}{*}{$53 \mathrm{~cm}$} \\
\hline $8 \mathrm{~cm}$ & Binder Tabakas1 & \\
\hline $40 \mathrm{~cm}$ & Plent-mix Temel & \\
\hline $10 \mathrm{~cm}$ & $\begin{array}{c}\text { Zemin+\% } \\
(\text { CBR \%60B2 } 20)\end{array}$ & \\
\hline & Zemin (CBR \%16) & \\
\hline
\end{tabular}

Çizelge 7 ve Çizelge 8 incelendiğinde üstyapıya etkiyen trafik yükünün artmasıyla birlikte kalınlıklar arasındaki farkın da artmış olduğu görülmektedir. Iğdır-Ağrı arası yolda kalınlık 5 $\mathrm{cm}$ azalmışken, Hatay-Kahramanmaraş arası yolda stabilizasyonlu zeminle stabilizasyonsuz zemin arası tabaka kalınlığı temel katmanında olmak üzere $12 \mathrm{~cm}$ 'lik bir azalmaya gitmiştir. $\mathrm{Bu}$ da Plent-mix temelin tabaka kalınlığının yaklaşık \%23 oranında azalmış olduğunu göstermektedir. 
Zaten trafik yükünün daha yüksek olduğu yol kesimlerimde zemin iyileştirmesinin daha verimli olması beklenen bir sonuçtur.

\section{SONUÇLAR}

$\mathrm{Bu}$ çalışmada zeminin C60B2 türü katyonik bir asfalt emülsiyonu ile stabilize edilmesi sonucu zemin taşıma gücündeki artış deneysel olarak çalışılmıştır. Ayrıca bu artışın esnek üstyapıya etkileri 2015 y1lı trafik istatistikleri dikkate alınarak seçilen bölgeler için AASHTO 93 yöntemi ile hesaplanmıştır. Araştırma verilerine göre aşağıdaki sonuçlara ulaşılmıştır.

- Stabilizasyonu yapılan iki tip zeminden ince malzeme oranı daha yüksek olan A tipi zeminin taşıma gücü B tipi zemininkine göre daha yüksek olarak bulunmuştur.

- Her iki tip zeminde de C60B2 katyonik asfalt emülsiyonu ile en uygun stabilizasyon oran1 $\% 4$ olarak tespit edilmiştir.

- Stabilizasyon yapılmamış A tipi zeminin CBR değeri \%18,09 iken, \%4 C60B2 katyonik asfalt emülsiyonu ile stabilize edilmesi sonrası CBR değeri \%24,05 olarak hesaplanmıştır.

- Stabilizasyon yapılmamış B tipi zeminin CBR değeri \%13,47 iken, \%4 C60B2 katyonik asfalt emülsiyonu ile stabilize edilmesi sonrası CBR değeri \%20,72 olarak hesaplanmıştır.

- Iğdır-Ağrı arası 2015 yılı trafik verilerine göre tasarlanmış karayolu esnek üstyapısında, CBR artışına bağlı olarak toplam tabaka kalınlığında 5 cm'lik bir azalma olduğu belirlenmiştir.

- Yıllık ortalama günlük trafik verileri daha yüksek olan Hatay-Kahramanmaraş arası devlet yolunda yapılan esnek üstyap 1 tasarımında ise üstyapı kalınlığ $12 \mathrm{~cm}$ azalmıştır.

- Zeminin C60B2 katyonik asfalt emülsiyonu ile stabilizasyonunun trafik istatistiklerinin daha yüksek olduğu Hatay-Kahramanmaraş arası tasarlanan yolda daha verimli olduğu söylenebilir.
- Uygulanan stabilizasyon her iki zemin tipi için de CBR değerini arttırmış olmakla birlikte ileriki çalışmada maliyet hesabı yapılarak trafik yükü ile bağlantılı olacak şekilde tabaka kalınlığından yapılan tasarruf ile stabilizasyon maliyetlerine dayalı öneriler geliştirilebilir.

\section{KAYNAKLAR}

1. Uzuner, B.A., 1995. Temel Mühendisliğine Giriş, Derya Kitabevi, Trabzon, 139.

2. Kök, B.V., Yılmaz, M., Geçkil, A., 2012. Çimento Stabilizasyonlu Zeminin Esnek Üstyap1 Maliyetine Etkisi, Pamukkale Üniversitesi Mühendislik Bilimleri Dergisi, 165-172.

3. Şenol, A., Edil, T.B., Bin-Shafique, M.S., Acosta, H.A., Benson, C.H., 2006. Soft Subgrades' Stabilization by Using Various Fly Ashes. Resources, Conservation and Recycling. 46, 365-376.

4. Eren, S., Filiz, M., 2009. Comparing the Conventional Soil Stabilization Methods To The Consolid System Used as an Alternative Admixture Matter in Isparta Darıdere Material. Construction and Building Materials. 23, 2473-2480.

5. Kolias, S., Kasselouri-Rigopoulou, V., Karahalios, A., 2005. Stabilisation of Clayey Soils With High Calcium Fly Ash and Cement. Cement \& Concrete Composites. 27, 301-313.

6. Orhan, F., 2012. Karayolları Genel Müdürlüğü Bitümlü Karışımlar Laboratuvarı Çalışmaları, Ankara, 12-13.

7. Umar, F., Ağar, E., 1985. Yol Üstyapıs1, İTÜ Yayınları.

8. Cilason, N., 1964. Toprak Stabilizasyonu, K.G.M., Yayın No: 122, Ankara.

9. TS 1900, 1987. İnşaat Mühendisliğinde Zemin Laboratuvar Deneyleri, Ankara.

10. TS 1082, 1974. İnşaat Mühendisliğinde Zemin Laboratuvar Deneyleri, Ankara.

11.TS EN 13808, 2013. İnşaat Mühendisliğinde Zemin Laboratuvar Deneyleri, Ankara.

12. Tunç, A., 2004. Kaplama Mühendisliği ve Uygulamaları, Asil Yayın Dağıtım, Ankara, 279.

13. KGM, 2016. 2015 Trafik ve Ulaşım Bilgileri, Trafik Güvenliği Dairesi Başkanlığı, Ankara. 
